\title{
Adaptive Voltage Control of the DC/DC Boost Stage in PV Converters with Small Input Capacitor
}

\author{
Andoni Urtasun, Student Member, IEEE, Pablo Sanchis, Senior Member, IEEE, \\ and Luis Marroyo, Member, IEEE
}

\begin{abstract}
In the case of photovoltaic (PV) systems, an adequate $P V$ voltage regulation is fundamental in order to both maximize and limit the power. For this purpose, a large input capacitor has traditionally been used. However, when reducing that capacitor size, the nonlinearities of the PV array make the performance of the voltage regulation become highly dependent on the operating point. This paper analyzes the nonlinear characteristics of the PV generator and clearly states their effect on the control of the DC/DC boost stage of commercial converters by means of a linearization around the operating point. Then, it proposes an adaptive control, which enables the use of a small input capacitor preserving at the same time the performance of the original system with a large capacitor. Experimental results are carried out for a commercial converter with a $40 \mu \mathrm{F}$ input capacitor, and a $4 \mathrm{~kW} \mathrm{PV}$ array. The results corroborate the theoretical analysis; they evidence the problems of the traditional control, and they validate the proposed control with such a small capacitor.
\end{abstract}

Index Terms-Adaptive control, photovoltaic converters, photovoltaic power systems, small-signal modeling, voltage control.

\section{INTRODUCTION}

$\mathrm{P}$ HOTOVOLTAIC systems are undergoing continuous expansion and development, both in grid-connected and isolated applications [1]. When connected to the grid, the PV array generally operates under Maximum Power Point Tracking (MPPT). However, the current trends toward distributed power generation systems based on renewable energy are leading to the introduction of microgrids [2], [3]. In such systems, it might be necessary to reduce the photovoltaic power in order to contribute to grid stability. A technique being able to function below the MPP by tracking a reference power must then be used [4]. We will refer to this technique as Limited Power Point Tracking (LPPT). In the same way, in an isolated system, the PV array usually operates under MPPT. Yet, it needs to limit the power and switches to LPPT when the storage element is full and the demand is low [5].

There are many MPPT algorithms in the literature [6], [7]. The most commonly used are perturbation and observation $(\mathrm{P \& O})$ [2], [8], hill-climbing [3], [9], fractional open-circuit

This work was supported in part by the Spanish Ministry of Economy and Competitiveness under Grants DPI2009-14713-C03-01 and DPI2010-21671C02-01 and by the Public University of Navarra.

The authors are with the Department of Electrical and Electronic Engineering, Public University of Navarra, Pamplona, Spain (e-mail: andoni. urtasun@unavarra.es; pablo.sanchis@unavarra.es; luisma@unavarra.es). voltage [10], and incremental conductance [11], [12]. Some of these algorithms have already been modified making it possible to operate both in MPPT and LPPT [5], [13].

The output reference of these algorithms can be the PV voltage [13]-[17], the PV current [18], [19], or just the duty cycle of the DC/DC converter [5]. However, excluding low power applications, it is well-known that the best option is to control the PV voltage since it changes slowly and it is more stable. Controlling the PV current can result in a voltage drop during the transients and controlling the duty cycle leads to an inappropriate control of PV voltage and current as well as to more losses and stresses in the converter [14]-[16], [20], [21].

The value of the PV voltage reference is continuously updated by the MPP or LPP tracker. Whilst in MPPT operation the PV voltage is very close to the MPP voltage, in LPPT operation the PV voltage varies from the MPP to the open circuit voltage [13]. Thus, a fast and stable regulation in the entire operating range is required for a proper tracking [15], [16]. However, the nonlinear nature of the photovoltaic array can cause the performance of the regulation to change with the operating point. Depending on the conversion structure, the control strategy and the input capacitor size, this nonlinear characteristic can lead to great variations in the dynamics and can even put the stability at risk [15], [16], [22], [23].

The variability in the PV voltage control process is caused by the dynamic resistance, which is obtained from the slope of its I-V curve [24], [25]. This parameter depends on the characteristics of the PV array, and is highly variable with the irradiation, the temperature and especially with the PV voltage. As a result, the voltage regulation performance can be diminished when operating under MPPT because of the irradiation and temperature change, and it can become even worse when operating under LPPT since the PV voltage also changes.

The influence of the dynamic resistance on the PV voltage control for a buck converter has been quite studied. In [16], the authors analyze the single and cascaded feedback loops. In both cases, a proper control is guaranteed in the whole operation range thanks to high cutoff frequencies and a big input capacitor. An in-depth analysis of the cascaded control technique is developed in [26] and [27]. It is shown that the system can become unstable if a correct regulation and capacitor sizing are not carried out [23], [26], [27].

The effect of the dynamic resistance on the control of a 
boost converter has been less analyzed in the literature. In [15], the authors regulate the PV voltage by means of the duty cycle, i.e. without inner current loop. These control schemes are usually applied to small PV generators (e.g. $50 \mathrm{~W}$ in [15]). In these systems, the influence of the dynamic resistance results in a very variable damping factor of the duty cycle to voltage transfer function. However, the undamped natural frequency hardly changes and the system can be easily controlled with a second order controller with no appreciable changes in the regulation performance [15], [28].

Other controls for low-power boost converters use a cascaded control. In [29], the authors employ a sliding mode control and a capacitor current sensor in order to both eliminate the dynamic resistance influence and achieve a very fast voltage response, making it possible to reject abrupt irradiance variations. Nevertheless, this strategy requires an additional current sensor in order to measure the input capacitor current.

For higher power boost converters (typically over $1 \mathrm{~kW}$ ), the PV voltage is usually controlled by means of an inner inductor current loop. The cascaded control avoids current transients and reduces failure rates. In these systems, the influence of the dynamic resistance has not been traditionally taken into account. The current to voltage transfer function has been considered as $1 / C s$, where the PV array is taken as a current source [17], [30]. Initially, the dynamic resistance effect was hidden by the use of large input capacitors. In recent years, these large electrolytic capacitors are being replaced by smaller polypropylene ones, which are much cheaper and more reliable [31], [32]. However, this capacitor reduction makes the dynamic resistance not negligible anymore. This renders necessary the analysis of the dynamic resistance effect and the design of new control techniques capable of compensating this effect.

This paper analyzes first, the influence of the dynamic resistance for the DC/DC boost stage of a typical single-phase PV converter. It is shown how the dynamic resistance diminishes the performance of the PV voltage regulation. The paper then proposes an adaptive control in order to obtain a PV voltage regulation with a cutoff frequency and a phase margin that remain almost constant for the whole operating range, in a system with a small input capacitor. The dynamic resistance is estimated from measured variables of the converter, namely the PV voltage and inductor current, and the controller is continuously adapted making use of that estimation.

\section{SYSTEM MODELING}

The analyzed system is shown in Fig. 1. It consists of a PV array, an input capacitor $(C)$, a boost converter, a bus capacitor $\left(C_{b u s}\right)$ and a single-phase inverter. There are two cascaded regulations, one for the inverter and another for the boost converter. The inverter controls the grid current with the desired power factor and maintains a constant bus voltage. This paper only deals with the cascaded regulation of the boost converter, which consists of an outer PV voltage loop and an inner inductor current loop.

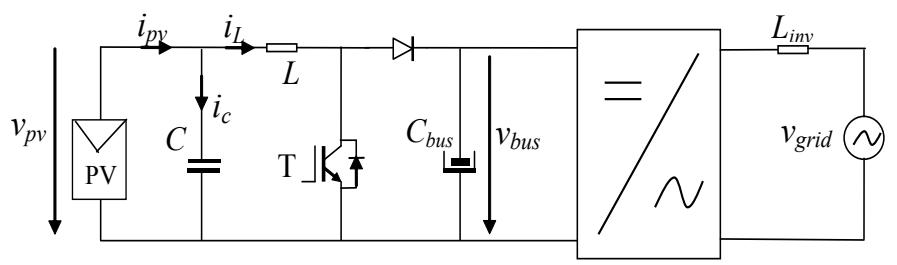

Fig. 1. PV single-phase conversion system

\section{A. Inductor current control}

Since it might be necessary to operate in LPPT with low inductor current, the control must be able to handle both the Continuous Conduction Mode (CCM) and the Discontinuous Conduction Mode (DCM). For this purpose, the current control is based on the technique proposed in [30] and [33], valid for both conduction modes. As it is shown below, using that strategy, the input impedance has no influence on the current control.

From Fig. 1, considering average values for all variables in a commutation period, the CCM and Kirchhoff's voltage law:

$$
v_{p v}-(1-d) \cdot v_{b u s}=L \cdot \frac{d i_{L}}{d t}
$$

where $d$ is the duty cycle.

Dividing (1) by $v_{b u s}$ and reorganizing the equation, one finds:

$$
d-\left(1-\frac{v_{p v}}{v_{b u s}}\right)=d-d_{c c m}=L \cdot \frac{d i_{L}}{d t} \cdot \frac{1}{v_{b u s}}
$$

where $d_{c c m}$ is defined as:

$$
d_{c c m}=1-\frac{v_{p v}}{v_{b u s}}
$$

As it can be observed in (2) and (3), the influence of the PV array on the process is included in $d_{c c m}$. The value of $d_{c c m}$ can be estimated from the voltages $v_{p v}$ and $v_{b u s}$, which are measured variables. The obtained value, $d_{c c m, f f}$, can be used as feedforward compensation.

Making use of (2), (3) and this feedforward compensation, the loop for the inductor current regulation in CCM is shown in Fig. 2, where $C_{i}$ represents the controller, $S_{i}$ the current digital sampler and $H_{i}$ the inductor current sensing. In these schemes, a bus voltage compensation has also been added by means of the bus voltage measurement, $v_{b u s, f}$.

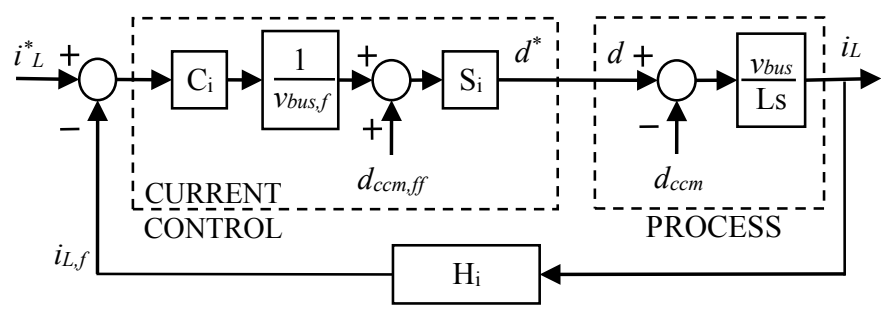

Fig. 2. Inductor current control loop for CCM

Being $T_{s i}$ the current sample time, the digital sampler $S_{i}$ can be approximated as [34]: 


$$
S_{i}(s)=\frac{1}{1.5 \cdot T_{s i} \cdot s+1}
$$

The inductor current sensing transfer function $H_{i}$ can be expressed as:

$$
H_{i}(s)=\frac{K_{i}}{\tau_{i} \cdot s+1}
$$

where $\tau_{i}$ is the time constant of the inductor current sensing and $K_{i}$ is the scaling constant of the inductor current sensing, which will be taken as 1 in order to simplify the analysis.

Because of the sampler and the retard in the measurements of $v_{p v}$ and $v_{b u s}$, the forwarded duty cycle $d_{c c m, f f}$ does not eliminate the effect of the PV generator for high frequencies. However, it is removed below the sample and sensing frequencies, and thus around the current control cutoff frequency. The process seen by the regulator can therefore be considered as $1 / L \mathrm{~s}$ for the controller design. A simple PI controller can then be used, obtaining a regulation independent of the dynamic resistance.

For the DCM, a similar analysis is carried out in [33], obtaining the same schemes of Fig. 2 but with a different equation for the duty cycle $d_{d c m}$ and for its estimation $d_{d c m, f f}$. In this case, only known variables of the system are also required for the estimation.

Since the boost converter can function in both conduction modes, the strategy constantly estimates both duty cycles $d_{c c m}$ and $d_{d c m}$. The authors prove that when operating in CCM, $d_{c c m}<d_{d c m}$ whereas in DCM, $d_{d c m}<d_{c c m}$. In other words, the lowest duty cycle correspond to the actual mode of conduction. As a result, the technique for both conduction modes uses the same schemes of Fig. 2 but choosing the minimum between $d_{c c m, f f}$ and $d_{d c m, f f}$ as feedforward compensation [33].

\section{B. Traditional Modeling of the PV Voltage Control Loop}

From Fig. 1 and Kirchhoff's current law:

$$
i_{p v}=i_{c}+i_{L}
$$

By replacing the capacitor current in (6):

$$
i_{p v}=C \cdot \frac{d v_{p v}}{d t}+i_{L}
$$

From (7) and by applying the Laplace transformation, the following current to voltage transfer function is obtained:

$$
\frac{v_{p v}(s)}{-i_{L}(s)+i_{p v}(s)}=\frac{1}{C \cdot s}
$$

Making use of (8), the loop for the PV voltage $v_{p v}$ regulation is shown in Fig. 3, where $C_{v}$ represents the controller, $S_{v}$ the voltage digital sampler, $H_{v}$ the PV voltage sensing, $G_{i c l}$ the current closed-loop, $g$ the irradiance, and $T$ the array temperature.

As it can be observed in the figure, the influence of the PV array on the process is now caused by the PV current $i_{p v}$. As in the case of the current control by means of the duty cycle (which depends on the PV voltage $v_{p v}$ ), a straightforward solution to remove the effect of the dynamic resistance would be to compensate the PV current $i_{p v}$. However, this current is not usually measured by the converter and an additional sensor would be required. For this reason, the feedforward compensation of $i_{p v}$ is not considered in this paper for the PV voltage control.

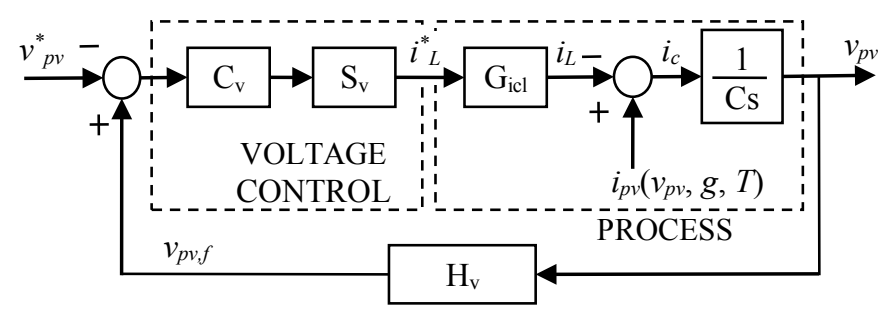

Fig. 3. Traditional PV voltage control loop

Being $T_{s v}$ the voltage sample time, the digital sampler $S_{v}$ can be approximated as [34]:

$$
S_{v}(s)=\frac{1}{1.5 \cdot T_{s v} \cdot s+1}
$$

The PV voltage sensing transfer function $H_{v}$ can be expressed as:

$$
H_{v}(s)=\frac{K_{v}}{\tau_{v} \cdot s+1}
$$

where $\tau_{v}$ is the time constant of the PV voltage sensing and $K_{v}$ is the scaling constant of the PV voltage sensing, which will be taken as 1 in order to simplify the analysis.

If the inner current and outer voltage loops are totally decoupled, the inner closed-loop could be modeled as 1 [17]. Although the loops are decoupled in this paper, the inner closed-loop will be modeled as a first order for more precision. Being $\omega_{i c}$ the angular cutoff frequency of the current control, the transfer function of the inductor current closed-loop is:

$$
G_{i c l}(s)=\frac{1}{s / \omega_{i c}+1}
$$

Traditionally, the PV current $i_{p v}$ has been considered as a disturbance and therefore independent of the variables that take part in the control. Although the current variation caused by the irradiation and the temperature is decoupled from the regulation, this is not the case for the current variation induced by the PV voltage, which cannot be considered as a disturbance and must be taken into account in the transfer function. For this purpose, the PV array will be modeled in section $\mathrm{C}$ and next, in section $\mathrm{D}$, its effect will be added to the transfer function.

\section{PV Array Modeling}

The curve I-V of a PV array can be expressed as [16]:

$$
i_{p v}=I_{p h}-I_{0} \cdot\left(\exp \left[\frac{v_{p v}+R_{s} \cdot i_{p v}}{V_{t}}\right]-1\right)-\frac{v_{p v}+R_{s} \cdot i_{p v}}{R_{p}}
$$

where $I_{p h}$ and $I_{0}$ are the photogenerated and saturation current of the array, $R_{s}$ is the equivalent series resistance, $R_{p}$ is the equivalent shunt resistance, and $V_{t}$ is the thermal voltage, 
which is defined as:

$$
V_{t}=N_{s} \cdot m \cdot \frac{k \cdot T}{q}
$$

where $N_{s}$ is the cells connected in series, $m$ is the ideality factor of the diode, $k$ is the Boltzmann constant, $T$ is the generator temperature, and $q$ is the electron charge.

To obtain a linear equation for the PV current $i_{p v}$ as a function of the PV voltage $v_{p v}$ and the irradiation $g$, some parameters are defined. The variation of the current with the temperature is not considered since it changes very slowly, being easily compensated by the regulator. The dynamic resistance of the array $R_{p v}$, which represents the voltage influence, is calculated using (12) as:

$$
R_{p v}=-\frac{\partial v_{p v}}{\partial i_{p v}}=R_{d} / / R_{p}+R_{s}
$$

where $R_{d}$ is defined as:

$$
R_{d}=\frac{V_{t}}{I_{0}} \cdot \exp \left(-\frac{v_{p v}+R_{s} \cdot i_{p v}}{V_{t}}\right)
$$

Similarly, the PV current coefficient of variation with the irradiation, referred to as $K_{g}$, is worked out using (12) as:

$$
K_{g}=\frac{\partial i_{p v}}{\partial g}=\left(1-\frac{R_{s}}{R_{p v}}\right) \cdot \frac{\partial I_{p h}}{\partial g}
$$

Thus, the linear model for the operating point with a PV current $I^{\prime}{ }_{0}, \mathrm{PV}$ voltage $V_{0}$, irradiation $G_{0}$ and generator temperature $T_{0}$ is:

$$
i_{p v}-I_{0}^{\prime}=K_{g} \cdot\left(g-G_{0}\right)-\frac{v_{p v}-V_{0}}{R_{p v}}
$$

where $R_{p v}$ and $K_{g}$ are evaluated for $\left(V_{0}, G_{0}, T_{0}\right)$.

Reordering (17), one finds:

$$
i_{p v}=I_{e q}+K_{g} \cdot g-\frac{v_{p v}}{R_{p v}}
$$

where $I_{e q}$ is the equivalent current comprising the constant terms, expressed as follows:

$$
I_{e q}=I_{0}^{\prime}-K_{g} \cdot G_{0}+\frac{V_{0}}{R_{p v}}
$$

The nonlinear I-V curve of the array and its linearization around the MPP are shown in Fig. 4. The curve reproduces (12) for the PV array of Table II (presented below) and given $G_{0}=1000 \mathrm{~W} / \mathrm{m}^{2}$ and $T_{0}=25^{\circ} \mathrm{C}$. The linearization around the MPP is based on (18).

The linear model can also be represented by an electrical circuit. The equivalent circuit, valid at the linearization point, is illustrated in Fig. 5.

By means of (14) and (16), both parameters $R_{p v}$ and $K_{g}$ depend on the PV array (features of the panel and number of panels connected in series and in parallel) and on the operating point. For a certain PV array, they are variable with the irradiation, the temperature and especially with the PV voltage. From (14) and (15), it can be observed that the dynamic resistance increases as the voltage decreases. Thus, it will be maximum for short-circuit:

$$
R_{p v}\left(v_{p v}=0, g, T\right)=R_{p}+R_{s} \approx R_{p}
$$

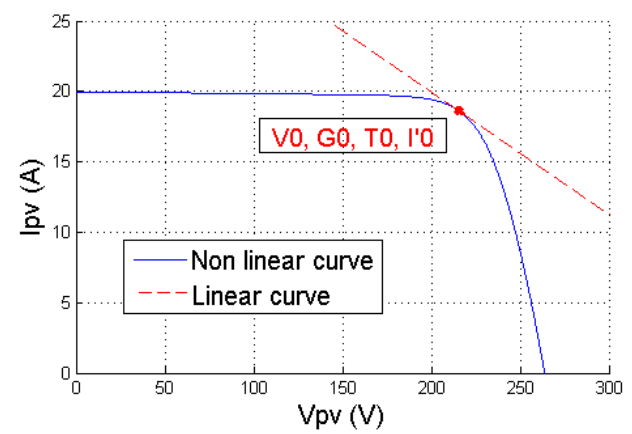

Fig. 4. Nonlinear I-V curve and linearization at point $\left(V_{0}, G_{0}, T_{0}, I^{\prime} 0\right)$

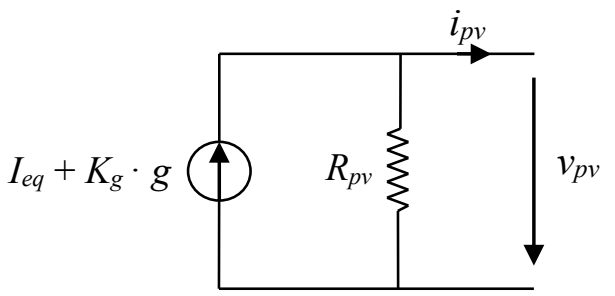

Fig. 5. Equivalent circuit at the linearization point

Likewise, it will be at a minimum for the open-circuit voltage. In that point, $R_{p}$ can be neglected and therefore:

$$
R_{p v}\left(v_{p v}=V_{o c}, g, T\right) \approx \frac{V_{t}}{I_{0}} \cdot \exp \left(-\frac{V_{o c}}{V_{t}}\right)+R_{s}
$$

Imposing the open-circuit condition in (12), $I_{p h}$ can be approximated as:

$$
I_{p h} \approx I_{0} \cdot \exp \left(\frac{V_{o c}}{V_{t}}\right)
$$

From (21) and (22) the dynamic resistance for $V_{o c}$ is finally worked out as:

$$
R_{p v}\left(v_{p v}=V_{o c}, g, T\right) \approx \frac{V_{t}}{I_{p h}}+R_{s}
$$

The dynamic resistance is shown in Fig. 6 and Fig. 7 for the PV array of Table II (presented below) and different irradiances and array temperatures, respectively. In both figures, $R_{p v}$ is represented as a function of the normalized voltage $v_{\text {norm }}$, which is defined as:

$$
v_{\text {norm }}=\frac{v_{p v}-V_{m p p}}{V_{o c}-V_{m p p}}
$$

where $V_{m p p}$ is the voltage at maximum power.

This normalized voltage is 1 for $v_{p v}=V_{o c}, 0$ for $v_{p v}=V_{m p p}$, and negative for $v_{p v}<V_{m p p}$. Since the PV voltage is near to $V_{m p p}$ when operating under MPPT and higher than $V_{m p \text { p }}$ when operating under LPPT, the dynamic resistance is represented for $v_{\text {norm }}>-0.4$. It can be observed in Fig. 6 and Fig. 7 that $R_{p v}$ decreases for high irradiances, high temperatures and high voltages. 


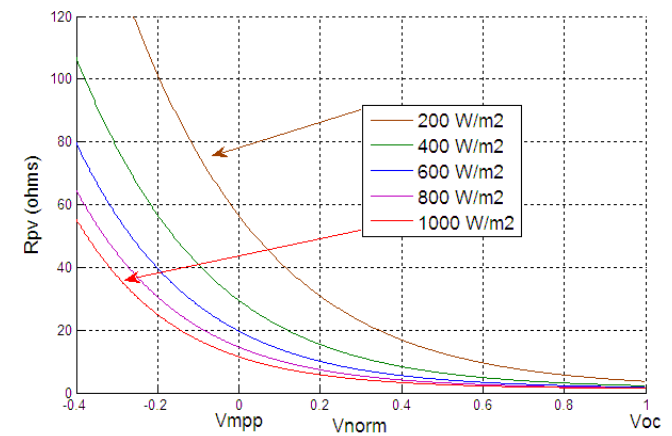

Fig. 6. Dynamic resistance versus normalized voltage for different irradiances at $\mathrm{T}=25^{\circ} \mathrm{C}$

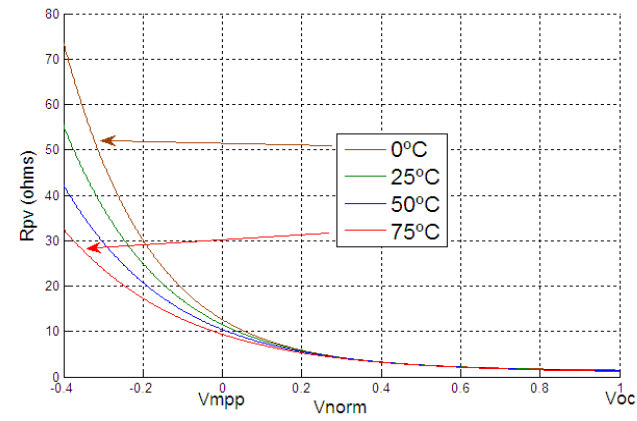

Fig. 7. Dynamic resistance versus normalized voltage for different temperatures and $\mathrm{g}=1000 \mathrm{~W} / \mathrm{m}^{2}$

\section{Small-Signal Modeling of the PV Voltage Control Loop}

The variables $v_{p v}, g$ and $i_{L}$ can be divided into their steadystate values (capitalized) and their small-signal values (marked with a hat):

$$
\begin{aligned}
& v_{p v}=V_{p v}+\hat{v}_{p v} \\
& g=G+\hat{g} \\
& i_{L}=I_{L}+\hat{i}_{L}
\end{aligned}
$$

By means of the linear model of the PV array expressed by (18), and (7), one finds:

$$
I_{e q}+K_{g} \cdot g-\frac{v_{p v}}{R_{p v}}=C \cdot \frac{d v_{p v}}{d t}+i_{L}
$$

The linear model is only valid when it is very close to the operating point, that is for the small-signal analysis. Introducing the definitions of (25) in (26):

$$
I_{e q}+K_{g} \cdot G+K_{g} \cdot \hat{g}-\frac{V_{p v}}{R_{p v}}-\frac{\widehat{v}_{p v}}{R_{p v}}=C \cdot \frac{d \hat{v}_{p v}}{d t}+I_{L}+\hat{i}_{L}
$$

From (27) and by applying the Laplace transformation, the following current to voltage transfer function is obtained:

$$
G_{v}(s)=\frac{\hat{v}_{p v}(s)}{-\hat{i}_{L}(s)+K_{g} \cdot \hat{g}(s)}=\frac{1}{C \cdot s+1 / R_{p v}}=\frac{R_{p v}}{C \cdot R_{p v} \cdot s+1}
$$

Using this transfer function, the loop for the PV voltage regulation becomes the one shown in Fig. 8. The obtained transfer function accounts for the PV current variation caused by the PV voltage. As a result, it models the behavior of the system more accurately than the traditional approach. In any case, the dynamic resistance is negligible and both transfer functions (8) and (28) are equivalent when $R_{p v} \cdot C \cdot \omega_{v c}>>1$, where $\omega_{v c}$ is the angular cutoff frequency of the voltage control. Thus, the traditional model is only valid when operating near to the short-circuit or with capacitances or voltage cutoff frequencies high enough. However, when the capacitor is reduced and taking into account that in real applications the cutoff frequency will be limited by the microprocessor and the inner current loop, the effect of the large variation range of $R_{p v}$ cannot be neglected.

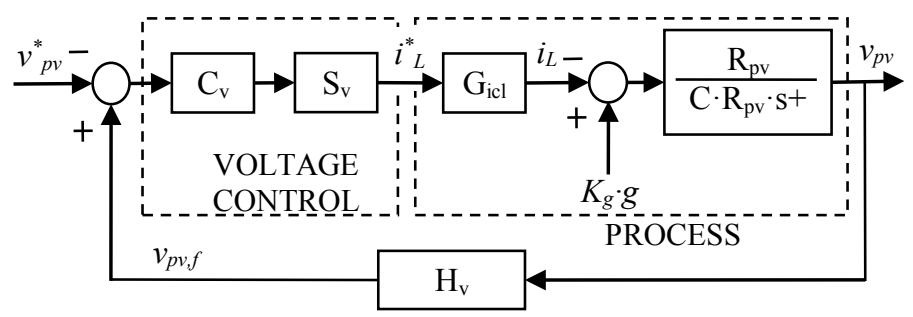

Fig. 8. PV voltage control loop

\section{TRADITIONAL CONTROL}

In this section, the variation of the regulation performance is studied for the boost stage of a typical PV converter, whose features are shown in Table I. The specifications of the PV array used for the analysis are shown in Table II.

The current control is carried out by means of the model developed in section II.A for a $450 \mathrm{~Hz}$ cutoff frequency and a $45^{\circ}$ phase margin. For the PV voltage regulation, a PI controller is used in the converter, as it is commonly carried out. Its parameters are calculated by means of the traditional modeling, depicted in Fig. 3, for a cutoff frequency $f_{v c}=50 \mathrm{~Hz}$ and a phase margin $P M_{v}=40^{\circ}$. The behavior of the system is now examined considering the effect of the dynamic resistance, using the modeling shown in Fig. 8. As it will be shown below, the dynamic resistance variation will make that the actual cutoff frequency $\left(f_{c}\right)$ and the actual phase margin $(P M)$ differ from their design values $\left(f_{v c}\right.$ and $\left.P M_{v}\right)$.

The Bode plots of the compensated system are represented in Fig. 9 for three characteristic operating points:

- $v_{p v}=0$ : In short-circuit, $R_{p v}$ reaches its maximum value, which is $R_{p v}=R_{p}=736 \Omega$ for the analyzed PV array (see (20)). Since $R_{p v} \cdot C \cdot \omega_{v c}>>1$, the influence of $R_{p v}$ is negligible and the actual cutoff frequency and phase margin are close to the design ones: $f_{c}=f_{v c}=50 \mathrm{~Hz}$ and $P M=46^{\circ} \approx P M_{v}$.

- $v_{p v}=V_{m p p}$ : In the MPP and for the nominal operating conditions $\left(g=800 \mathrm{~W} / \mathrm{m}^{2}, T=50^{\circ} \mathrm{C}\right), R_{p v}$ is equal to $13.18 \Omega$. In this case, the effect of the dynamic resistance is very significant and the regulation becomes much slower and more damped, with $f_{c}=5 \mathrm{~Hz}$ and $P M>90^{\circ}$.

- $v_{p v}=V_{o c}$ : In open-circuit, $R_{p v}$ reaches its minimum value, which is $R_{p v}=1.16 \Omega$ (see (23)) for the maximum irradiance $\left(g=1100 \mathrm{~W} / \mathrm{m}^{2}\right)$ and temperature $\left(T=75^{\circ} \mathrm{C}\right)$. The effect of $R_{p v}$ is enormous, slowing down the control to an actual cutoff frequency $f_{c}=0.4 \mathrm{~Hz}$ and with $P M>90^{\circ}$. 
TABLE I

FEATURES OF THE DC/DC BOOST STAGE OF A COMMERCIAL PV CONVERTER

\begin{tabular}{|c|c|}
\hline Nominal power & $5000 \mathrm{~W}$ \\
\hline Input capacitor $C$ & $40 \mu \mathrm{F}$ \\
\hline Boost inductor $L$ & $750 \mu \mathrm{H}$ \\
\hline Commutation frequency $f_{c}$ & $16 \mathrm{kHz}$ \\
\hline PV voltage sample time $T_{s v}$ & $250 \mu \mathrm{s}$ \\
\hline Inductor current sample time $T_{s i}$ & $125 \mu \mathrm{s}$ \\
\hline Time constant of the PV voltage sensing $\tau_{v}$ & $74 \mu \mathrm{s}$ \\
\hline Time constant of the inductor current sensing $\tau_{i}$ & $74 \mu \mathrm{s}$ \\
\hline Angular cutoff frequency of the current control $\omega_{i c}$ & $2 \pi \cdot 450 \mathrm{rad} / \mathrm{s}$ \\
\hline Bus voltage $V_{\text {bus }}$ & $350 \mathrm{~V}$ \\
\hline
\end{tabular}

TABLE II

SPECIFICATIONS OF THE PV ARRAY, FORMED BY 4 STRINGS OF 12 BP585 MODULES

\begin{tabular}{|c|c|}
\hline Nominal power & $4080 \mathrm{~W}$ \\
\hline MPP voltage $V_{m p p}$ & $216 \mathrm{~V}$ \\
\hline MPP current $I_{m p p}$ & $18.9 \mathrm{~A}$ \\
\hline Open-circuit voltage $V_{o c}$ & $264 \mathrm{~V}$ \\
\hline Short-circuit current $I_{s c}$ & $20 \mathrm{~A}$ \\
\hline Equivalent series resistance $R_{s}$ & $0.848 \Omega$ \\
\hline Equivalent shunt resistance $R_{p}$ & $736 \Omega$ \\
\hline Cells connected in series in a module $N_{s}$ & 36 \\
\hline Ideality factor $m$ & 1 \\
\hline
\end{tabular}

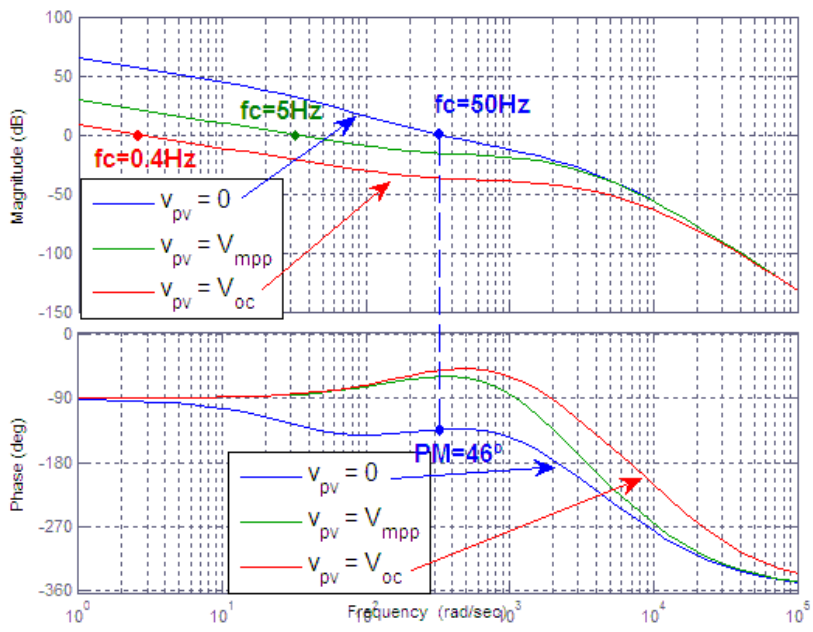

Fig. 9. Bode plots of the compensated system $C_{v} \cdot S_{v} \cdot G_{i c l} \cdot G_{v} \cdot H_{v}(C=40 \mu \mathrm{F})$

The effect of the capacitor size on the performance variation for the previously analyzed system is now examined in Fig. 10. This figure represents the actual cutoff frequency and phase margin of the voltage control as a function of $R_{p v}$ for three different capacitances $(40 \mu \mathrm{F}, 400 \mu \mathrm{F}$ and $4000 \mu \mathrm{F})$. In the three cases, the design cutoff frequency and phase margin are maintained to $f_{v c}=50 \mathrm{~Hz}$ and $P M_{v}=40^{\circ}$. The three characteristic operating points are marked with lines. The short-circuit (SC) is the only point where the actual cutoff frequency is equal to the design cutoff frequency $(50 \mathrm{~Hz})$ for the three capacitors. However, the system normally operates between the MPP and the open-circuit (OC). In that range, the performance variation highly depends on the capacitor size. In particular, for $C=40 \mu \mathrm{F}$ and the considered PV array, the cutoff frequency decreases from $5 \mathrm{~Hz}$ at MPP to $0.4 \mathrm{~Hz}$ at open-circuit; for $C=400 \mu \mathrm{F}$, the influence is lower, with the dynamics changing from $43.6 \mathrm{~Hz}$ at MPP to $4.4 \mathrm{~Hz}$ at opencircuit; and for $C=4000 \mu \mathrm{F}$, the effect of $R_{p v}$ is now almost negligible, with a variation from $50 \mathrm{~Hz}$ to $41.7 \mathrm{~Hz}$. This is the reason why, when using large electrolytic capacitors, it is not necessary to account for dynamic resistance influence on the system modeling. Regarding the stability of the control, the variation range is less critical, since the actual phase margin is always higher than the design one.
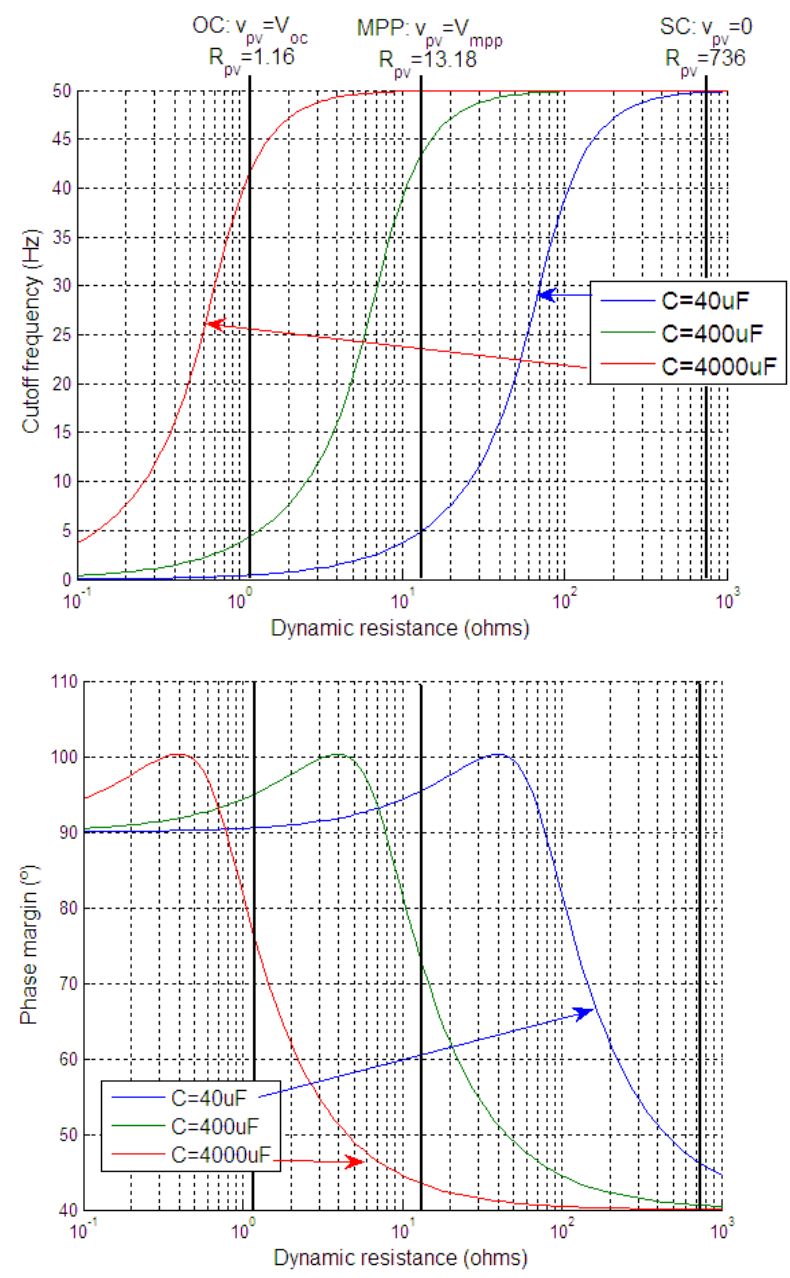

Fig. 10. Actual cutoff frequency and phase margin of the PV voltage regulation for three different capacitances $C(40 \mu \mathrm{F}, 400 \mu \mathrm{F}$ and $4000 \mu \mathrm{F})$ and with $f_{v c}=50 \mathrm{~Hz}$ and $P M_{v}=40^{\circ}$

The theoretical analysis carried out in this section has been verified by simulation. An accurate model of the PV array and the PV converter was developed using the software PSIM. In Fig. 11, the voltage response is represented for an irradiance of $1000 \mathrm{~W} / \mathrm{m}^{2}$, a temperature of $25^{\circ} \mathrm{C}$ and using a $40 \mu \mathrm{F}$ capacitor. It consists of downward steps of the PV voltage reference $\left(V p v \_r e f\right)$ from $260 \mathrm{~V}$, close to the open-circuit voltage $\left(V_{o c}=264 \mathrm{~V}\right)$, to $210 \mathrm{~V}$, below the MPP voltage $\left(V_{m p p}=216 \mathrm{~V}\right)$. The figure includes the theoretical values of $R_{p v}$ and $f_{c}$ for each reference voltage level. This dynamic resistance has been worked out by means of (14). From the obtained $R_{p v}$, the actual cutoff frequency has been obtained from Fig. 10. In the figure, the real value of the dynamic resistance is also represented. Considering the design cutoff frequency $f_{c v}=50 \mathrm{~Hz}$ and the traditional model of Fig. 3, the rise time of the voltage response should be constant and close to $9.5 \mathrm{~ms}$ (using $3 / \omega_{v c}$ ). 
However, as predicted, the rise time is much higher and strongly dependent on voltage level. For example, during the voltage transient from 260 to $250 \mathrm{~V}$, the rise time obtained by simulation is $730 \mathrm{~ms}$. This value indeed agrees with the prediction of the model, that is $853 \mathrm{~ms}\left(f_{c}=0.56 \mathrm{~Hz}\right)$ for $v_{p v}=260 \mathrm{~V}$ and $672 \mathrm{~ms}\left(f_{c}=0.71 \mathrm{~Hz}\right)$ for $v_{p v}=250 \mathrm{~V}$. Likewise, it can be verified that there is not overshoot, which means that the phase margin is very high. This also makes sense since the theoretical analysis shown in Fig. 10 predicted a phase margin higher than $90^{\circ}$.

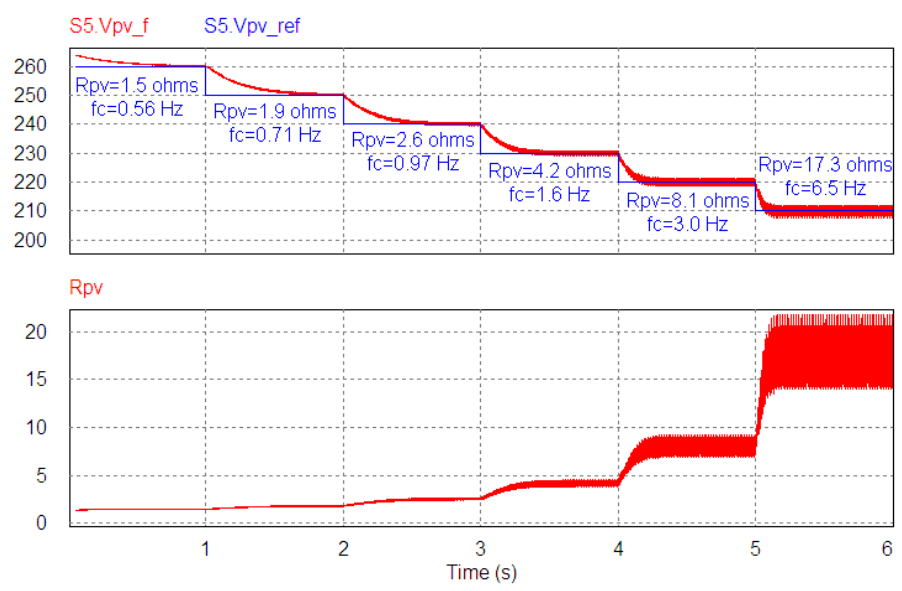

Fig. 11. Simulation of the PV voltage regulation with the traditional control $(C=40 \mu \mathrm{F})$ and with $f_{v c}=50 \mathrm{~Hz}$ and $P M_{v}=40^{\circ}$

It has been shown that, using small capacitors, the regulation becomes very slow for some operating points, which can lead to important problems such as poor behavior of the MPPT/LPPT, resonance phenomena or no rejection of irradiation variations. As a consequence, it is not recommendable to continue with a PI controller. A higherorder controller has also been considered, but the results did not improve.

\section{PRoposed CONTROL}

To solve the problems of the dynamic resistance variation, an adaptive control is proposed in this paper. For each voltage sample time $\left(T_{s v}\right)$, the control estimates the dynamic resistance and uses this value in order to adapt one parameter of the controller according to the dynamic resistance variation. In this way, the nonlinear system variability is compensated.

\section{A. Dynamic Resistance Estimation}

If a short period is considered, the linear model of the PV array is applicable (18). It can be seen that the $i_{p v}$ variation is caused by both $v_{p v}$ and $g$ variations. The irradiance variation is unknown but can have an important effect on the current during a cloud passage. This fact hinders the estimation of the dynamic resistance, which represents the current variation caused by the voltage variation. For this reason, an intrinsic feature of single-phase inverters, particularly its $100 \mathrm{~Hz}$ ripple, is used. In real systems, the irradiance component around the $100 \mathrm{~Hz}$ is negligible. As a result, the evolution of the $100 \mathrm{~Hz}$ ripple of $i_{p v}$ is exclusively provoked by the $100 \mathrm{~Hz}$ ripple of $v_{p v}$. From (18), one obtains:

$$
i_{p v 100}=K_{g} \cdot g_{100}-\frac{v_{p v 100}}{R_{p v}} \approx-\frac{v_{p v 100}}{R_{p v}}
$$

where $i_{p v 100,} g_{100}$ and $v_{p v 100}$ are, respectively, the PV current, irradiance and PV voltage obtained after applying a type I Chebyshev $100 \mathrm{~Hz}$ band-pass filter $(100 \mathrm{~Hz}$ BPF) to the original signal.

Now, an estimation of the dynamic resistance, $R_{p v, e s t}$, can be easily found by dividing the rms value of $v_{p v 100}\left(V_{p v 100}\right)$ by the rms value of $i_{p v 100}\left(I_{p v 100)}\right)$

$$
R_{p v, e s t}=\frac{V_{p v 100}}{I_{p v 100}}
$$

Generally, the measured current is $i_{L}$ instead of $i_{p v}$. However, $i_{p v 100}$ can be worked out by means of the $100 \mathrm{~Hz}$ ripple of $i_{L}\left(i_{L 100}\right)$ and $v_{p v 100}$ as follows:

$$
i_{p v 100}=i_{L 100}+C \cdot \frac{v_{p v 100}(k)-v_{p v 100}(k-1)}{T_{s v}}
$$

\section{B. Controller design}

The proposed controller is a second order one with two constant parameters $K_{p}$ and $T_{n}$ and one variable parameter $T_{m}$ :

$$
C_{v}(s)=K_{p} \cdot \frac{T_{n} \cdot s+1}{T_{n} \cdot s} \cdot \frac{T_{m} \cdot s+1}{T_{m} \cdot s}
$$

Multiplying the transfer function of the controller by the current to voltage transfer function $G_{v}$ (see (28)), one finds:

$$
C_{v}(s) \cdot G_{v}(s)=K_{p} \frac{T_{n} \cdot s+1}{T_{n} \cdot s} \frac{1}{C \cdot s} \frac{T_{m} \cdot s+1}{T_{m}} \frac{C \cdot R_{p v}}{C \cdot R_{p v} \cdot s+1}
$$

From (33), it is observed that, once the dynamic resistance is known, the variability of the system can be eliminated by means of the controller parameter $T_{m}$ by doing:

$$
T_{m}=C \cdot R_{p v, e s t}
$$

Furthermore, the product $C_{v}(\mathrm{~s}) \cdot G_{v}(\mathrm{~s})$ remains now the same as with a PI and the traditional model, and therefore $K_{p}$ and $T_{n}$ can be calculated as traditionally. In Fig. 12, the proposed control including the $R_{p v}$ estimation is shown.

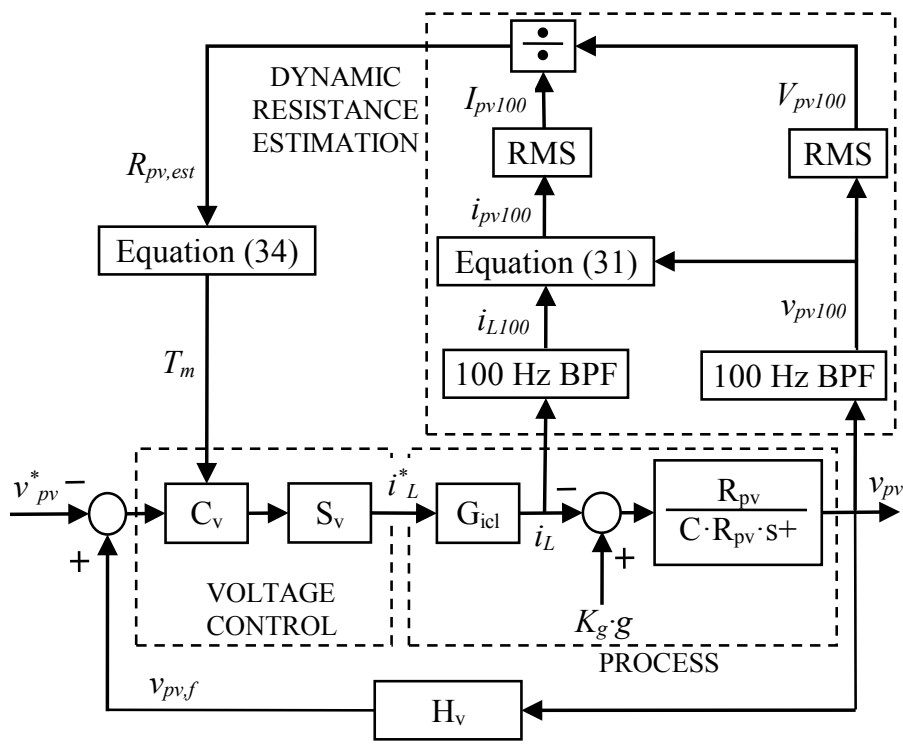

Fig. 12. Proposed PV voltage control loop 
This control has been validated by simulation with PSIM. The features of the simulated system are identical to the traditional control excluding that now, the proposed control is used. In addition, the design cutoff frequency for the voltage control is $f_{v c}=20 \mathrm{~Hz}$ and the phase margin is $P M_{v}=55^{\circ}$. The cutoff frequency is chosen quite lower than $100 \mathrm{~Hz}$ in order to avoid interactions with the $100 \mathrm{~Hz}$ ripple of the single-phase converters. Given that the bigger the PV array, the slower the average irradiance variation in the whole PV array, this cutoff frequency is high enough to perform a fast MPPT/LPPT and to reject the irradiance variations [35].

The performance of the control is shown in Fig. 13 for the same conditions of the test in Fig. 11 (note that the time scale is different). The real dynamic resistance and its estimation are also represented in the figure. Given that the design cutoff frequency is $20 \mathrm{~Hz}$, the rise time of the voltage response should be constant and close to $23.9 \mathrm{~ms}$ (using $3 / \omega_{v c}$ ). However, during the transient from 260 to $250 \mathrm{~V}$, i.e. near to open-circuit, the rise time is $18.4 \mathrm{~ms}$, whereas from 220 to $210 \mathrm{~V}$, around the MPP, it is $15.1 \mathrm{~ms}$. This deviation of the actual cutoff frequency from the design value is caused by the misestimation of $R_{p v}$. As it can be observed in the figure, the misestimation only occurs in transients due to a retard in the estimation of $R_{p v, e s t}$. In any case, when using the proposed control, the rise time is much closer to the design time than in the case of the traditional control, where it was expected to be $9.5 \mathrm{~ms}$ but varies from $730 \mathrm{~ms}$ near to open-circuit to $108 \mathrm{~ms}$ around the MPP (see Fig. 11). Furthermore, the rise time obtained with the proposed control is much lower despite having a lower design cutoff frequency $(20 \mathrm{~Hz}$ versus $50 \mathrm{~Hz})$. Thus, thanks to the proposed control, the MPPT/LPPT controller period can be considerably reduced, which leads to an improvement of its performance. More precisely, on account of the analysis of [29] for the stabilization time, the traditional control requires a MPPT/LPPT cycle of about 1 second whereas the proposed control can reduce this time up to about $40 \mathrm{~ms}$ ).
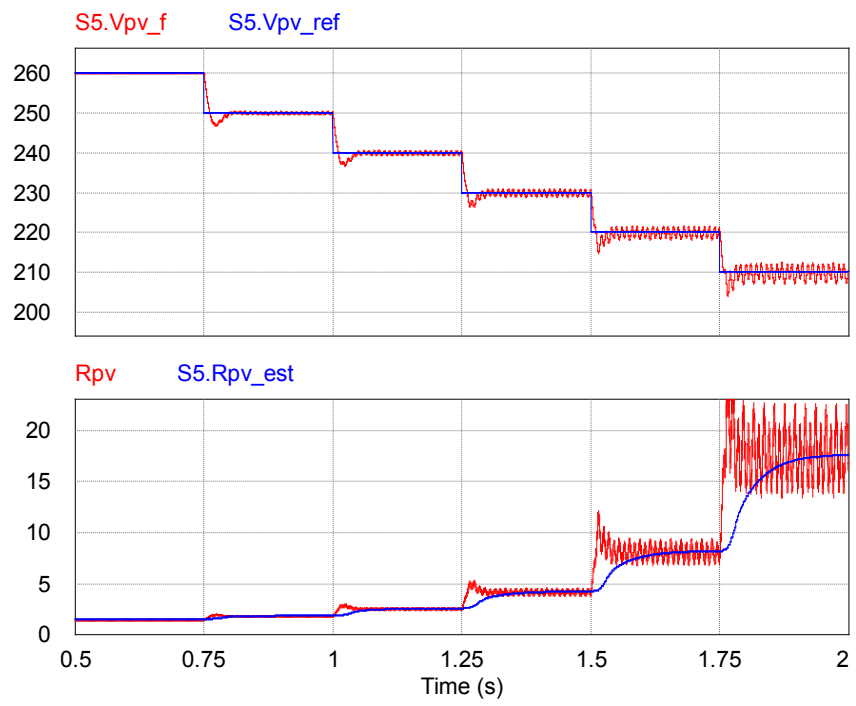

Fig. 13. Simulation of the PV voltage regulation with the proposed control

\section{EXPERIMENTAL RESULTS}

In this section, the modeling is validated and the traditional and proposed control strategies are tested using the commercial single-phase converter which was presented in Table I. Its input is connected to the PV array shown in Table II and its output is connected to the grid.

Modeling is first validated. From Fig. 8, the theoretical current reference to PV voltage transfer function $G_{v^{*}}$ can be obtained as follows:

$$
G_{v}^{*}(s)=G_{i c l}(s) \cdot G_{v}(s)=-\frac{1}{s / \omega_{i c}+1} \cdot \frac{R_{p v}}{R_{p v} \cdot C \cdot s+1}
$$

To validate this model, the voltage control loop is deactivated. For a sunny day, a current reference composed by a constant and a small-signal sinusoidal term is introduced. The constant component is adjusted in order to set the desired $v_{p v}$ operating point, i.e. the desired dynamic resistance. With the sinusoidal term, a frequency range is swept for that operating point. Then, the small-signal PV voltage response is measured, obtaining the gain for each frequency.

The experimental gain diagram of the Bode plot is represented in Fig. 14 for one operating point in each of the three different regions of the I-V curve: Constant Current (CC), Maximum Power Point (MPP), and Constant Voltage (CV). The lines represent the theoretical response given by (35) and the points represent the experimental values. As it can be observed, the experimental points match the theoretical model carried out in section II.

In this figure, the effect of the dynamic resistance on the plant can also be observed. In fact, the gain at low frequencies is equal to $R_{p v}$ itself. In addition, it can be observed the influence of the $G_{v}$ transfer function pole, which is located at a frequency of $200 \mathrm{rad} / \mathrm{s}$ in the CC, $1250 \mathrm{rad} / \mathrm{s}$ in the MPP, and $10000 \mathrm{rad} / \mathrm{s}$ in the $\mathrm{CV}$. The pole due to the current closed-loop is common and equal to $2850 \mathrm{rad} / \mathrm{s}$.

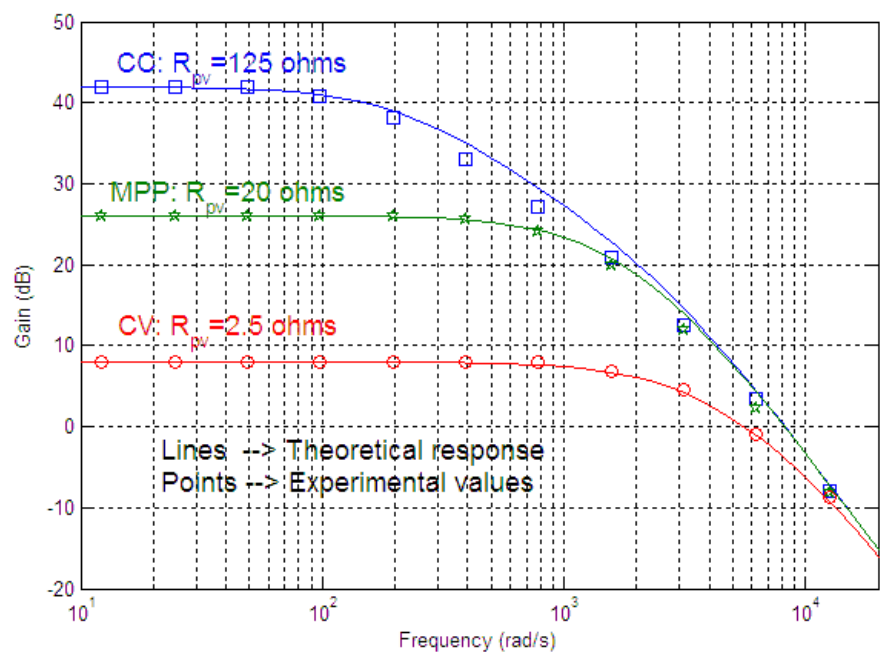

Fig. 14. Gain of the reference inductor current to PV voltage transfer function $G_{v^{*}}$ at three operating points

The traditional control is now tested by maintaining the original configuration of the converter; that is, with the design 
values of $f_{v c}=50 \mathrm{~Hz}$ and $P M_{v}=40^{\circ}$ (as in section III). The PV voltage and the PV current are depicted in Fig. 15 for steps of the voltage reference. At the moment of this test, the conditions were: $g=820 \mathrm{~W} / \mathrm{m}^{2}, T=51^{\circ} \mathrm{C}$, and $V_{o c}=227 \mathrm{~V}$. It can be observed that the regulation speeds up when reducing the voltage since it increases the dynamic resistance. More precisely, the rise time is $660 \mathrm{~ms}$ near to the open-circuit, then $470 \mathrm{~ms}, 310 \mathrm{~ms}$ and finally $130 \mathrm{~ms}$ around the MPP. Similarly to the simulation results (Fig. 11), these rise times validate the slowing down of the control for high values of the PV voltage.

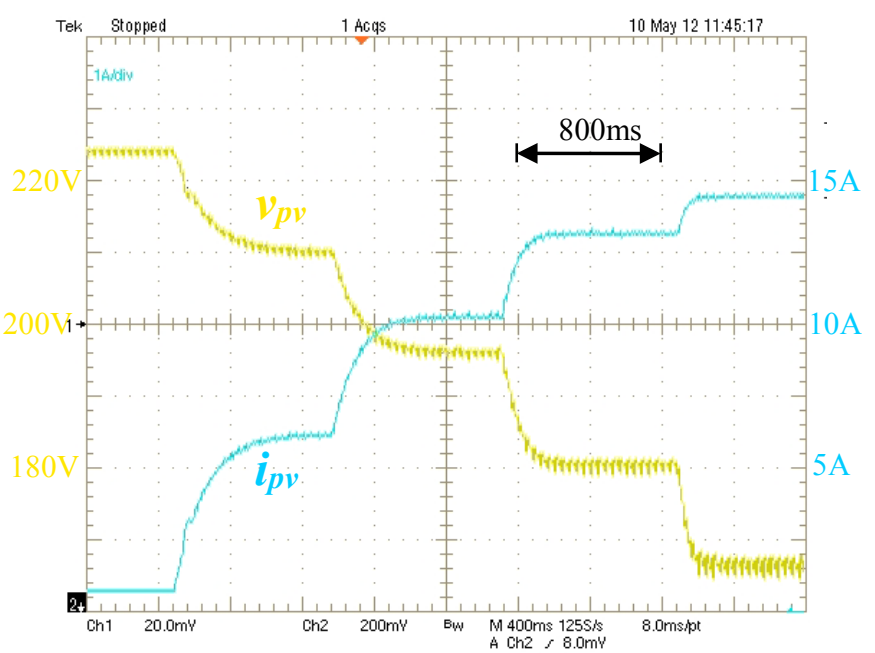

Fig. 15. Experimental results for the traditional control

Modifying the converter configuration, the same test was carried out by means of the proposed control, with $f_{v c}=20 \mathrm{~Hz}$ and $P M_{v}=55^{\circ}$ (as in section IV). At that moment, the conditions were: $g=700 \mathrm{~W} / \mathrm{m}^{2}, T=49^{\circ} \mathrm{C}$, and $V_{o c}=228 \mathrm{~V}$. The results are presented in Fig. 16, showing that dynamics and overshoot of the regulation remain almost constant independently of $R_{p v}$. More precisely, the rise time is $20.5 \mathrm{~ms}$ near to the open-circuit, then $18.5 \mathrm{~ms}, 16.8 \mathrm{~ms}$ and finally $14.3 \mathrm{~ms}$ around the MPP. This figure confirms, in contrast to the traditional control, that the regulation performance is almost constant independently of the operating point.

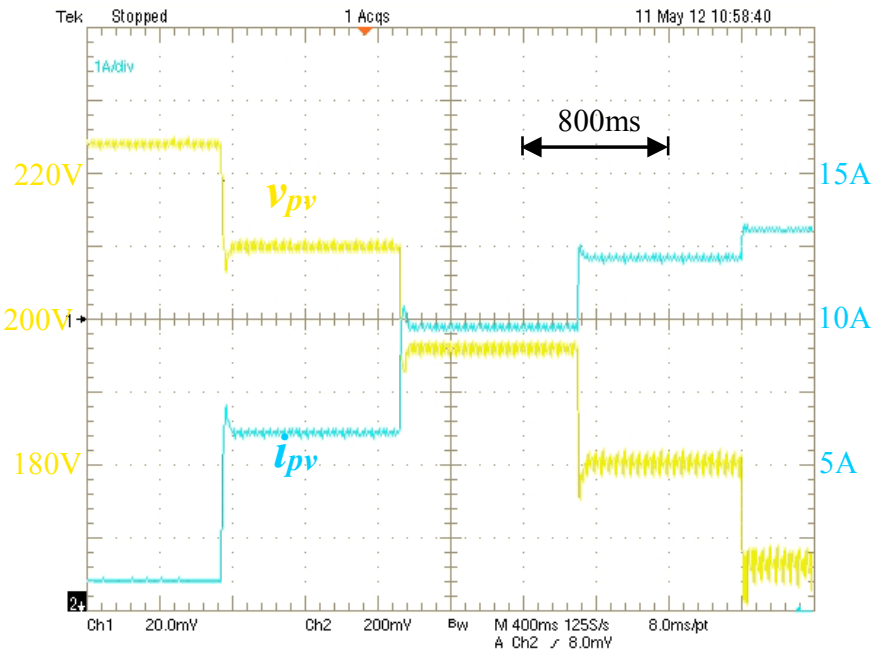

Fig. 16. Experimental results for the proposed control
In Fig. 17, the $100 \mathrm{~Hz}$ ripple of $v_{p v}$ and $i_{p v}\left(v_{p v 100}\right.$ and $\left.i_{p v 100}\right)$, and the estimation of the dynamic resistance are represented. The data are taken from the microprocessor during normal operation, with a sample time of $250 \mu \mathrm{s}$. It can be seen that $v_{p v 100}$ and $i_{p v 100}$ are accurately obtained. As a result, the dynamic resistance is well estimated even for very low $100 \mathrm{~Hz}$ ripple. This small ripple makes it possible to perform a highefficient MPPT while preventing the components from a lifetime reduction. More precisely, on account of the ripple shown in Fig. 13 and 16 at MPP, and considering [36], the losses under MPPT are less than $0.1 \%$.

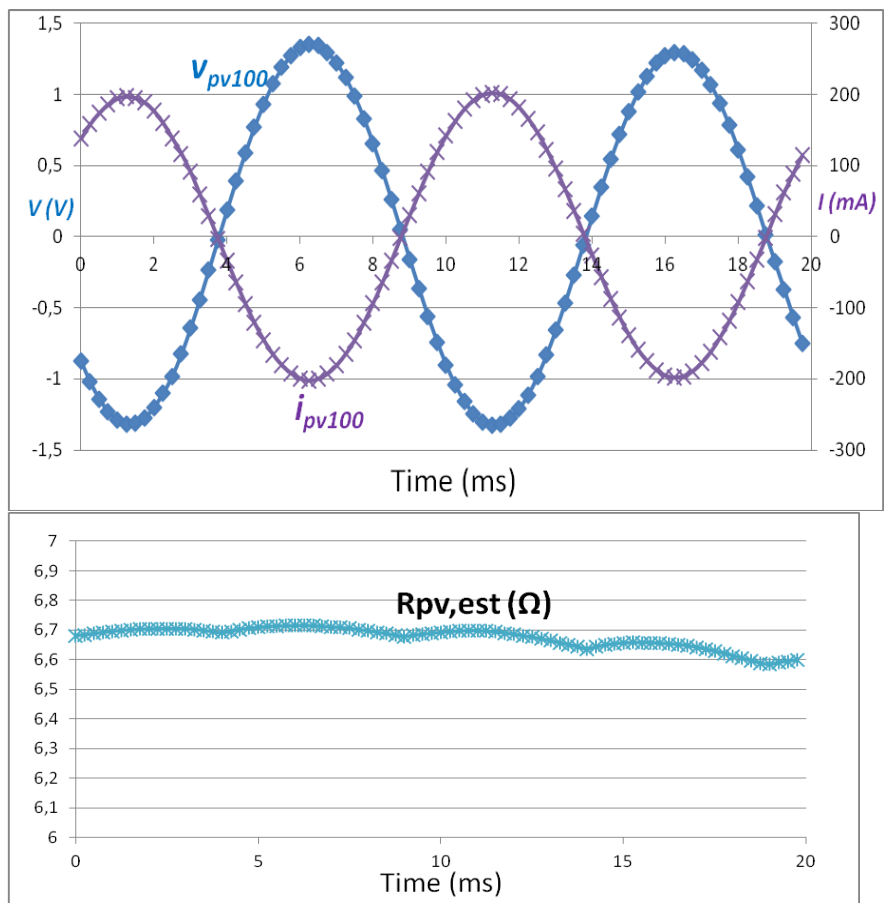

Fig. 17. Experimental results for the dynamic resistance estimation

\section{CONCLUSIONS}

In PV systems, the PV voltage regulation depends on the dynamic resistance, which changes with the characteristics of the PV array and it is highly variable with the irradiation, the temperature and especially with the PV voltage. In traditional control loops for the DC/DC boost stage of PV converters with large input capacitor, the effect of the dynamic resistance variation on the dynamic response of the compensated system is negligible. However, in the last years, the input capacitor of the commercial converters has been reduced in order to cut costs, which has brought the performance of the voltage regulation highly dependent on the operating point.

By means of a linearization of the PV array, this paper exposes how the dynamic resistance reduces the performance of the regulation to a high extent when a small capacitor is used. In order to avoid that variability, an adaptive control is proposed. The dynamic resistance is firstly estimated from measured variables of the converter, namely the PV voltage and the inductor current. Then, the controller is continuously adapted making use of the estimation. The resistance is 
accurately calculated by means of the voltage and current $100 \mathrm{~Hz}$ ripple present in single-phase inverters. This avoids misestimations caused by abrupt irradiance variations.

The traditional control and the proposed control are tested using a commercial converter with a small $40 \mu \mathrm{F}$ input capacitor, and a $4 \mathrm{~kW}$ PV array. The experimental results validate the theoretical analysis, show the problems of the traditional control, and demonstrate the better performance of the proposed control and the correct estimation of the dynamic resistance

\section{ACKNOWLEDGEMENT}

The authors gratefully acknowledge INGETEAM POWER TECHNOLOGY for their financial and permanent support.

\section{REFERENCES}

[1] J. Campillo and S. Foster, "Global Solar Photovoltaic Industry Analysis with Focus on the Chinese Market," Mälardalen University, Märdalen, Sweden, Student Thesis, 2008.

[2] A. K. Abdelsalam, A. M. Massoud, S. Ahmed, and P. N. Enjeti, "HighPerformance Adaptive Perturb and Observe MPPT Technique for Photovoltaic-Based Microgrids," IEEE Transactions on Power Electronics, Vol. 26, Issue 4, pp. 1010-1021, 2011.

[3] B. N. Alajmi, K. H. Ahmed, S. J. Finney, and B. W. Williams, "FuzzyLogic-Control Approach of a Modified Hill-Climbing Method for Maximum Power Point in Microgrid Standalone Photovoltaic System," IEEE Transactions on Power Electronics, Vol. 26, Issue 4, pp. 10221030, 2011.

[4] H. F. Wedde, S. Lehnhoff, E. Handschin, and O. Krause, "Establishing Large-Scale Renewable Reserve Capacity through Distributed MultiAgent Support," $5^{\text {th }}$ IEEE International Conference on Industrial Informatics, Vol. 2, pp. 1157-1163, 2007.

[5] L. D. Watson and J. W. Kimball, "Frequency Regulation of a Microgrid Using Solar Power," Twenty-sixth annual IEEE Applied Power Electronics Conference and Exposition (APEC), pp. 321-326, 2011.

[6] T. Esram and P. L. Chapman, "Comparison of Photovoltaic Array Maximum Power Point Tracking Techniques," IEEE Transactions on Energy Conversion, Vol. 22, Issue 2, pp. 439-449, 2006.

[7] S. Jain and V Agarwal, "Comparison of the performance of maximum power point tracking schemes applied to single-stage grid-connected photovoltaic systems," IET Electric Power Applications, Vol. 1, Issue 5, pp. $753-762,2007$.

[8] N. Femia, G. Petrone, G. Spagnuolo, and M. Vitelli, "Optimization of Perturb and Observe Maximum Power Point Tracking Method," IEEE Transactions on Power Electronics, Vol. 20, Issue 4, pp. 963-973, 2005.

[9] W. Xiao and W. G. Dunfort, "A Modified Adaptive Hill Climbing MPPT Method for Photovoltaic Power Systems," 35th Annual IEEE Power Electronics Specialists Conference (PESC), Vol. 3, pp 1957 1963, 2004.

[10] K. Kohayashi, H. Matsuo, and Y. Sekine, "A Novel Optimum Operating Point Tracker of the Solar Cell Power Supply System," 35th Annual IEEE Power Electronics Specialists Conference (PESC), Vol. 3, pp 2147-2151, 2004.

[11] Q. Mei, M. Shan, L. Liu, and J. M. Guerrero, "A Novel Improved Variable Step-Size Incremental-Resistance MPPT Method for PV Systems," IEEE Transactions on Industrial Electronics, Vol. 58, Issue 6, pp. 2427-2434, 2011.

[12] A. Safari and S. Mekhilef, "Simulation and Hardware Implementation of Incremental Conductance MPPT With Direct Control Method Using Cuk Converter," IEEE Transactions on Industrial Electronics, Vol. 58, Issue 4, pp. 1154-1161, 2011.

[13] V. A. K. Pappu, B. Chowdhury, and R. Bhatt, "Implementing frequency regulation capability in a solar photovoltaic power plant," North American Power Symposium (NAPS), pp. 1-6, 2010.

[14] T. Suntio, J. Leppäaho, J. Huusari, and L. Nousiainen, "Issues on SolarGenerator Interfacing With Current-Fed MPP-Tracking Converters,"
IEEE Transactions on Power Electronics, Vol. 25, Issue 9, pp. 24092419, 2010.

[15] W. Xiao, W. G. Dunford, P. R. Palmer, and A. Capel, "Regulation of Photovoltaic Voltage," IEEE Transactions on Industrial Electronics, Vol. 54, Issue 3, pp. 1365-1374, 2007.

[16] M.G. Villalva, T.G. de Siqueira, and E. Ruppert, "Voltage regulation of photovoltaic arrays: small-signal analysis and control design," IET Power Electronics, Vol. 3, Issue 6, pp. 869-880, 2010.

[17] R. Kadri, J. Gaubert, and G. Champenois, "An Improved Maximum Power Point Tracking for Photovoltaic Grid-Connected Inverter Based on Voltage-Oriented Control," IEEE Transactions on Industrial Electronics, Vol. 58, Issue 1, pp. 66-75, 2011.

[18] T. Esram, J. W. Kimball, P.T. Krein, P.L. Chapman, and P. Midya, "Dynamic Maximum Power Point Tracking of Photovoltaic Arrays Using Ripple Correlation Control," IEEE Transaction on Power Electronics, Vol. 21, Issue 5, pp. 1282-1291, 2006.

[19] T. Suntio, J. Leppäaho, and J. Huusari, "Issues on Solar-GeneratorInterfacing with Voltage-Fed Converter," $35^{\text {th }}$ Annual Conference of IEEE Industrial Electronics (IECON'09), pp. 595-600, 2009.

[20] P. de Assis Sobeira, M. G. Villalva, P. G. Barbosa, H. A. C. Braga, J. R. Gazoli, E. Ruppert, and A. A. Ferreira, "Comparative analysis of current and voltage-controlled photovoltaic Maximum Power Point tracking," Brazilian Power Electronics Conference, pp. 858-863, 2011.

[21] M. G. Villalva, J. R. Gazoli, and E. R. Filho, "Analysis and simulation of the P\&O MPPT algorithm using a linearized PV array model," $35^{\text {th }}$ Annual Conference of IEEE Industrial Electronics (IECON'09), pp. 231-236, 2009.

[22] M. G. Villalva and E. R. Filho, "Dynamic analysis of the inputcontrolled buck converter fed by a photovoltaic array," Sba Controle \& Automação, Vol. 19, Issue 4, 2008.

[23] J. Puukko, L. Nousiainen, and T. Suntio, "Effect of Minimizing Input Capacitance in VSI-Based Renewable Energy Source Converters," Telecommunications Energy Conference (INTELEC), pp. 1-9, 2011.

[24] J. Thongprona, K. Kirtikara, and C. Jivacate, "A Method for the Determination of Dynamic Resistance of Photovoltaic Modules under Illumination," Solar Energy Materials and Solar Cells, Vol. 90, pp. 3078-3084, 2006

[25] A. Mäki, S. Valkealahti, T. Suntio, "Dynamic Terminal Characteristics of a Photovoltaic Generator," 14th International Power Electronics and Motion Control Conference, pp. T12-76 - T12-80, 2010.

[26] L. Nousiainen, J. Puukko, and T. Suntio, "Appearance of a RHP-Zero in VSI-Based Photovoltaic Converter Control Dynamics," Telecommunications Energy Conference (INTELEC), pp. 1-8, 2011.

[27] L. Nousiainen, J. Puukko, and T. Suntio, "Simple VSI-Based SinglePhase Inverter: Dynamical Effect of Photovoltaic Generator and Multiplier-Based Grid Synchronization," IET Conference on Renewable Power Generation, pp. 1-6, 2011

[28] L. Nousiainen, J. Puukko, A. Mäki, T. Messo, J. Huusari, J. Jokipii, J. Viinamäki, D. T. Lobera, S. Valkealahti, and T. Suntio, "Photovoltaic Generator as an Input Source for Power Electronic Converters", IEEE Transactions on Power Electronics, Vol. x, Issue x, pp. x, x.

[29] E. Bianconi, J. Calvente, R. Giral, E. Mamarelis, G. Petrone, C. A. Ramos-Paja, G. Spagnuolo, and M. Vitelli, "A Fast Current-Based MPPT Technique Employing Sliding Mode Control," IEEE Transactions on Power Electronics, Vol. 60, Issue 3, pp. 1168-1178, 2013.

[30] J. L. Agorreta, L. Reinaldos, R. González, M. Borrega, J. Balda, and L. Marroyo, "Fuzzy Switching Technique Applied to PWM Boost Converter Operating in Mixed Conduction Mode for PV Systems," IEEE Transactions on Industrial Electronics, Vol. 56, Issue 11, pp. 4363-4373, 2009.

[31] G. Petrone, G. Spagnuolo, R. Teodorescu, M. Veerachary, and M Vitelli, "Reliability Issues in Photovoltaic Power Processing Systems," IEEE Transactions on Industrial Electronics, Vol. 55, Issue 7, pp. 25692580, 2008

[32] S. V. Dhople, A. Davoudi, A. D. Domínguez-García, P. L. Chapman, "A Unified Approach to Reliability Assessment of Multiphase DC-DC Converters in Photovoltaic Energy Conversion Systems," IEEE Transactions on Power Electronics, Vol. 27, Issue 2, pp. 739-751, 2012.

[33] Koen De Gussemé, David M. Van de Sype, Alex P. M. Van den Bossche, Jan A. Melkebeek, "Digitally Controlled Boost Power-FactorCorrection Converters Operating in Both Continuous and Discontinuous 
Conduction Mode". IEEE Transactions on Industrial Electronics, Vol. 52, Issue 1, pp. 88-97, 2005.

[34] K. Jalili and S. Bernet, "Design of LCL Filters of Active-Front-End Two-Level Voltage-Source Converters," IEEE Transactions on Industrial Electronics, Vol. 56, Issue 5, pp. 1674-1689, 2009.

[35] J. Marcos, L. Marroyo, E. Lorenzo, D. Alvira, and E. Izco, "Power output fluctuations in large scale pv plants: One year observations with one second resolution and a derived analytic model," Progress in Photovoltaics, Vol. 19, Issue 2, pp. 218-227, 2011.

[36] C. R. Sullivan, J. J. Awerbuch, and A. M. Latham, "Decrease in Photovoltaic Power Output from Ripple: Simple General Calculation and the Effect of Partial Shading", IEEE Transactions on Power Electronics, Vol. 2, Issue 2, pp. 740-747, 2013J.

\section{BIOGRAPHIES}

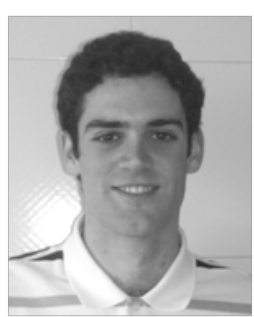

Andoni Urtasun (S'11) was born in Pamplona, Spain, in 1987. He received the M.Sc. degree in electrical engineering from the Public University of Navarre, Pamplona, Spain, and from the Institut National Polytechnique de Toulouse, Toulouse, France, both in 2010 .

In 2010, he joined the Electrical Engineering, Power Electronics and Renewable Energy research group, Public University of Navarre, where he is currently pursuing his Ph.D. His research interests include power electronics and hybrid renewable energy systems.

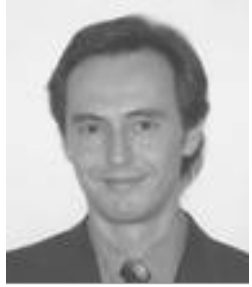

Pablo Sanchis (M'03) received the M.Sc. and Ph.D. degrees in electrical engineering in 1995 and 2002, respectively, and the M.Sc. degree in management and business administration in 1994, all from the Public University of Navarra, Pamplona, Spain.

From 1996 to 1998, he worked as a Guest Researcher at Delft University of Technology, The Netherlands, on the field of control of electric machines. In 1998, he joined the Department of Electrical and Electronic Engineering at the Public University of Navarra, Spain, where he is currently Associate Professor. He is also Director of the Renewable Energies Space and Vice Dean of the College of Engineering of this university.

Dr. Sanchis is member of the IEEE, the IET, the CIGRE and the Spanish Hydrogen Association (AEH2). He has been involved in many research projects mainly in co-operation with industry. His research interests include renewable energies, power electronics, hydrogen technologies, electric grid integration and electric microgrids.

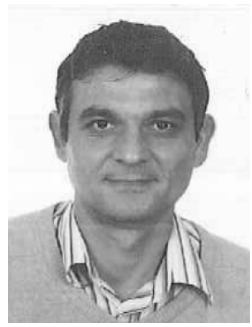

Luis Marroyo (M'04) received the M.Sc. degree in electrical engineering in 1993 from the University of Toulouse, France, and the Ph.D. degree in electrical engineering in 1997 from the UPNA, Spain, and in 1999 from the LEEI-ENSEEIHT INP Toulouse, France. From 1993 to 1998, he was Assistant Professor at the Department of Electrical and Electronic Engineering of the UPNA, where he currently works as Associate Professor, since 1998. $\mathrm{He}$ is the head of the INGEPER research group. He has been involved in more than 60 research projects mainly, in co-operation with industry, he is the co-inventor of 11 international patents and coauthored of more than 70 papers in international journals and conferences. His research interests include power electronics, grid quality and renewable energy. 